\title{
ESTABLISHMENT OF D-Q REFERENCE FRAME THROUGH DFIG DERIVED FROM PI AND ANN CONTROLLER
}

\begin{abstract}
The global electrical energy consumption is rising in our day-to-day and there is a sudden increase in the demand of the power generation. Large number of the renewable energy units is now being integrated in the power system for meeting and the rising demand of power generation. Slip ring induction machine is the variable speed in the wind turbine popularly said as double fed induction generator is mostly used in wind power generation. The main reason for the popularity of the doubly fed wind induction generation is connected to the power network is their ability to supply power at the constant voltage and frequency while the rotor speed varies and motor converter handles fraction of the stator power. The main aim of this paper is to design doubly fed induction generation (DIFG) and to control the rotor and the stator voltages by injecting the proper rotor voltage to the DIFG derived from $\mathrm{PI}$ and ANN controller so as to appropriate d-q reference frame is established to investigate simulation.
\end{abstract}

Key words: Artificial Neural Networks, DFIG, Dynamic Model, Stationary Reference frame, Wind Power Generation.

\section{INTRODUCTION}

Energy is main criteria for human development in any country. Any country that can produce energy in large scale can become a developed country in a short time. Mainly energy sources can be divided into two categories. Renewable energy sources and Non-renewable energy sources. Alternatively energy sources are the energy sources different from those in wide spread use at the moments (which are referred to as conventional). Alternative energy sources include solar, wind, wave, and tidal, hydroelectric and geothermal energy. Although they each have their own drawbacks, none of these energy sources produces significant air pollution, unlike conventional sources. Their energy is only oxygen in air to form carbon dioxide or carbon monoxide and water. Other elements within the fuels are also released into the air after combining with oxygen causing further pollution with $\mathrm{SO}_{2}$ and nitrogen oxide gasses. In the case of coal, ash particles are also a problem. Non-renewable energy sources that exist in a limited amount on earth. Thus all available material could eventually be completely used up. Coal, Oil and gas are considered as non-renewable energy sources because the rate of their formation is so slow on human time scales that they are using them without being replaced. Generally wind energy is available in abundance. For conversion of this wind energy into electrical energy and induction generator is coupled with a wind mill offers an ideal solution. Wind energy is available in abundance in our environment. When compared with the conventional sources of energy, wind energy is clean, efficient, and sustainable form of energy. When the cost of supplying electricity to remote locations is expensive, wind energy provides a cost effective 
alternative. So to convert this wind energy into electrical energy, an induction generator will offer an ideal solution.

\section{DOUBLY FED INDUCTION GENERATOR}

Wind turbine use as DFIG (Doubly fed induction generator). So wound rotor of induction generator and then ac-dc-ac bases of IGBT PWM converter. Stator winding is directly connected to the $50 \mathrm{~Hz}$ grid. So the rotor is fed at variable frequency through ac-dc-ac converter. This technology allows the maximum extracting energy from the wind through low wind speed by the process of optimizing the turbine speed. The optimum turbine speed producing maximum mechanical energy for a given wind speed is proportional to wind speed. So another advantage of this DFIG is ability for power electronic convertor to generate the reactive power, thus removing the need of installing capacitor banks as in case of squirrel cage induction generator.

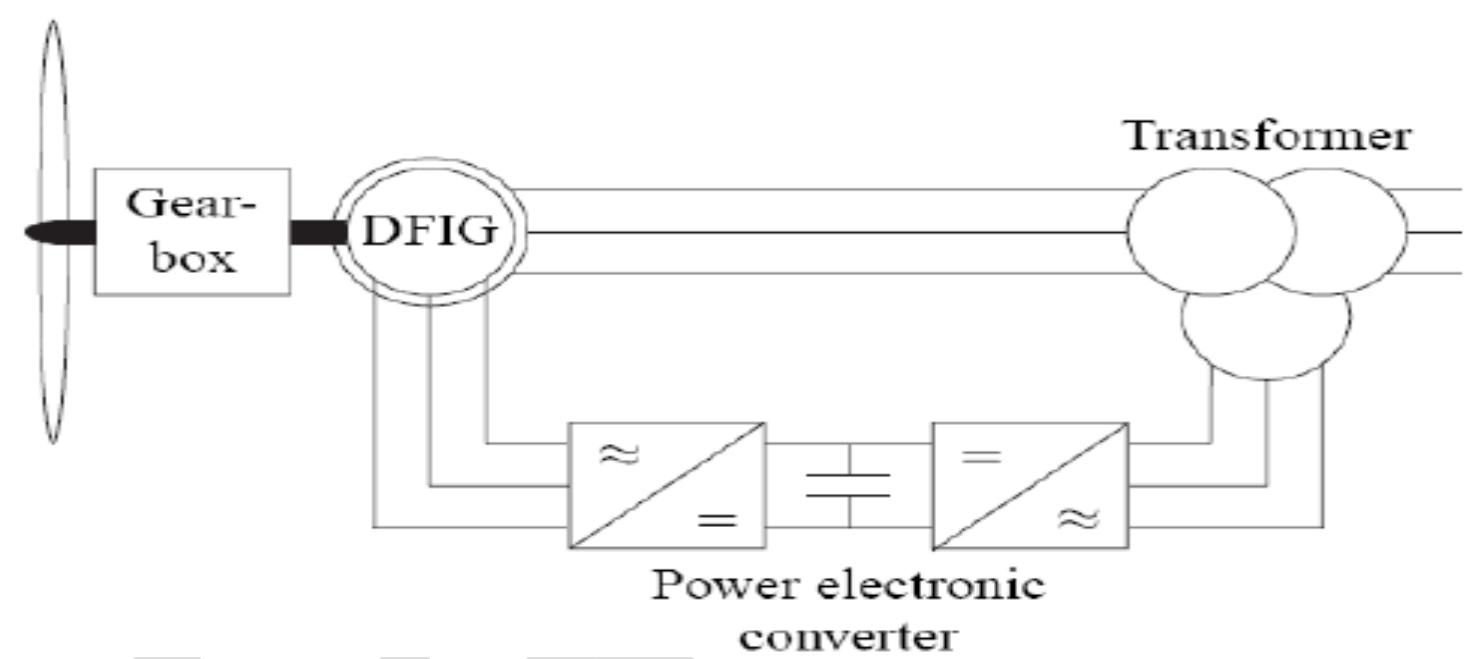

Fig 1.Variable-speed wind turbine with a doubly-fed induction generator (DFIG)

\section{A. Operating principle of DFGI}

The stator is directly connected to the main of A.C . The wound rotor is fed from the power electronic converter with slip ring so to allow by DFIG to operate at the variety of the speed in response to changing wind speed. Indeed the basic concept to interpose a frequency grid. The DC capacitor linking stator and the rotor side.

$\operatorname{Pr}=\mathrm{Tm} * \omega \mathrm{r}$.

Ps $=$ Tem* $\omega \mathrm{s}$

For the loss of less generator the mechanical equation is

$\mathrm{J}(\mathrm{d} \omega \mathrm{r} / \mathrm{dt})=\mathrm{Tm}-\mathrm{Tem}$

In steady-state at the fixed speed for a loss less generator

$\mathrm{Tm}=\mathrm{Tem}$ and $\mathrm{Pm}=\mathrm{Ps}+\mathrm{Pr}$

And it follows that:

$\mathrm{Pr}=\mathrm{Pm}-\mathrm{Ps}=\mathrm{Tm} \omega \mathrm{r}-\mathrm{Tem} * \omega \mathrm{s}=-\mathrm{S}$ Ps

Where

$\mathrm{S}=(\omega \mathrm{s}-\omega \mathrm{r}) / \omega \mathrm{s}$ is defines as the slip of the generator 


\section{B. Back-to-Back AC/DC/AC Converter Modeling}

Mathematical modeling of converter system is realized by using various types of models, which can be broadly divided into two groups there are mathematical functional models and Mathematical physical models (either equation-oriented or graphic-oriented, where graphic-oriented approach is actually based on the same differential equations).

\section{MATHEMATICAL REPRESENTATION OF DFIG}

An induction motor can be look like a transformer with a rotating secondary, where the coefficients of coupling between the stator and rotor phases change continuously with the change in the rotor position. The machine model can be described by differential equations with time varying mutual inductances, but such a model tends to be very complex, such as vector control, based on the dynamic d-q model of the machine. Therefore to understand vector control principle, a good understanding of d-q model is mandatory.

The transformation equation from a-b-c to this d-q-o reference frame is given by

$\mathrm{f}_{\mathrm{qdo}}=\mathrm{K}_{\mathrm{s}} *$ fabcs.

$$
\begin{aligned}
& \text { where, } \left.\quad \begin{array}{rl}
\left(\mathbf{f}_{\boldsymbol{f}} d 0 s\right. \\
\left(\mathbf{f}_{a b c s}\right)^{T}
\end{array}\right)^{T}=\left[\begin{array}{lll}
f_{a s} & f_{d s} & f_{0 s}
\end{array}\right] \text {, } \\
& \mathbf{K}_{s}=\frac{2}{3}\left[\begin{array}{ccc}
\cos \theta & \cos \left(\theta-\frac{2 \pi}{3}\right) & \cos \left(\theta+\frac{2 \pi}{3}\right) \\
\sin \theta & \sin \left(\theta-\frac{2 \pi}{3}\right) & \sin \left(\theta+\frac{2 \pi}{3}\right) \\
\frac{1}{2} & \frac{1}{2} & \frac{1}{2}
\end{array}\right],
\end{aligned}
$$

Where the variable $f$ can be the phase voltages, current, or flux linkages of the machine. The transformation angle $\theta_{r}$ between the q-axis of the reference frame rotating at a speed of $\mathrm{w}$ and the a-axis of the stationary stator winding may be expressed as

$\theta=\int_{0}^{t} \cdot \omega(t) d t+\theta(\cdot):$

\section{A. qdo Torque Equations}

The sum of the instantaneous input power to all six windings of the stator and rotor is given by:

Pin $=$ Vas Ias + VbsIbs + VcsIcs + Var Iar+ VbrIbr+ VbrIbr.

Using stator and rotor voltages to substitute for the voltages on the right hand side of (4.8), we obtain three kindsof terms: $\mathrm{i}^{2} \mathrm{r}$, id $\psi / \mathrm{dt}$ and $\omega \psi \mathrm{i} .\left(\mathrm{i}^{2} \mathrm{r}\right)$ terms are the copper losses. The electromagnetic torque developed by the machine is given by the sum of the ( $\omega . \psi \mathrm{i})$ terms divide by mechanical speed, that is:

Tem $=(3 / 2)(\mathrm{p} / 2 \omega \mathrm{r})[\omega(\psi \mathrm{dsiqs}-\psi \mathrm{qs}$ ids $)+(\omega-\omega \mathrm{r})(\psi$ driqr- $\psi$ qridr $)]$.

Using the flux linkage relationships, Tem can also be expressed as follows:

$\mathrm{Tem}=(3 / 2)(\mathrm{p} / 2 \omega \mathrm{r})[\omega(\psi \mathrm{dsiqs}-\psi \mathrm{qs}$ ids $)+(\omega-\omega \mathrm{r})(\psi$ driqr- $\psi \mathrm{qridr})]$

Using the flux linkage linkage relationships, one can show that

$\mathrm{Tem}=(3 / 2)(\mathrm{p} / 2)[(\psi \mathrm{qridr}-\psi$ driqr $)]$

$=(3 / 2)(\mathrm{p} / 2)[(\psi$ dsiqs- $\psi \mathrm{qs}$ ids $)]$

$=(3 / 2)(\mathrm{p} / 2) \operatorname{Lm}[($ idriqs- iqr ids $)]$ 
One can rearrange the torque equations by inserting the inserting the speed voltage terms given below:

Eqs $=\omega \psi \mathrm{ds} \quad \mathrm{Eds}=-\omega \psi \mathrm{qs}$

$\mathrm{Eqr}=(\omega-\omega \mathrm{r}) \psi \mathrm{dr} \quad \mathrm{Edr}=-(\omega-\omega \mathrm{r}) \psi \mathrm{qr}$

\section{a. Induction Machine Equations in Stationary Reference Frame}

Stator circuit equations:

$\mathrm{Vqs}^{\mathrm{s}}=\mathrm{d} / \mathrm{dt}\left(\psi \mathrm{qs}^{\mathrm{s}}\right)+\mathrm{rsiqs}^{\mathrm{s}}$

$V \mathrm{ds}^{\mathrm{s}}=\mathrm{d} / \mathrm{dt}\left(\psi \mathrm{ds}^{\mathrm{s}}\right)+\mathrm{rsids}^{\mathrm{s}}$

Rotor circuit equations:

$\mathrm{Vqr}^{\mathrm{s}}=\mathrm{d} / \mathrm{dt}\left(\psi \mathrm{qr}^{\mathrm{s}}\right)+\mathrm{rriqr}^{\mathrm{s}}$

$\mathrm{Vdr}^{\mathrm{s}}=\mathrm{d} / \mathrm{dt}\left(\psi \mathrm{dr}^{\mathrm{s}}\right)+\mathrm{rridr}^{\mathrm{s}}$

Flux linkage equations:

$\psi \mathrm{qs}^{\mathrm{s}}=\mathrm{Llsiqs}^{\mathrm{s}}+\mathrm{Lm}\left(\mathrm{iqs}^{\mathrm{s}}+\mathrm{iqr}^{\mathrm{s}}\right)=(\mathrm{Lls}+\mathrm{Lm}) \mathrm{iqs}^{\mathrm{s}}+\mathrm{Lmiqr}^{\mathrm{s}}=\mathrm{Ls}$ iqs $\mathrm{s}^{\mathrm{s}}+\mathrm{Lmiqr}^{\mathrm{s}}$

$\psi q^{\mathrm{s}} \mathrm{r}^{\mathrm{s}}=\mathrm{Llriqr}^{\mathrm{s}}+\mathrm{Lm}\left(\mathrm{iqs}^{\mathrm{s}}+\mathrm{iqr}^{\mathrm{s}}\right)=(\mathrm{L} 1 \mathrm{r}+\mathrm{Lm}) \mathrm{iqr}^{\mathrm{s}}+\mathrm{Lmiqs}^{\mathrm{s}}=\mathrm{Ls}^{\mathrm{s}} \mathrm{iqr}^{\mathrm{s}}+\mathrm{Lmiqs}^{\mathrm{s}}$

$\psi \mathrm{ds}^{\mathrm{s}}=\mathrm{Llsids}^{\mathrm{s}}+\mathrm{Lm}\left(\mathrm{ids}^{\mathrm{s}}+\mathrm{idr}^{\mathrm{s}}\right)=(\mathrm{Lls}+\mathrm{Lm}) \operatorname{ids}^{\mathrm{s}}+\mathrm{Lmidr}^{\mathrm{s}}=\mathrm{Ls} \mathrm{ids}^{\mathrm{s}}+\mathrm{Lmidr}^{\mathrm{s}}$

$\psi \mathrm{dr}^{\mathrm{s}}=\mathrm{Llridr}^{\mathrm{s}}+\mathrm{Lm}\left(\mathrm{ids}^{\mathrm{s}}+\mathrm{idr}^{\mathrm{s}}\right)=(\mathrm{Llr}+\mathrm{Lm}) \operatorname{idr}^{\mathrm{s}}+\mathrm{Lmids}^{\mathrm{s}}=\mathrm{Lridr}^{\mathrm{s}}+\mathrm{Lmids}^{\mathrm{s}}$

\section{b. $d-q$ Torque Equations}

$\mathrm{Tem}=(3 / 2)(\mathrm{p} / 2)[(\psi \mathrm{qridr}-\psi$ driqr $)]$

$=(3 / 2)(\mathrm{p} / 2)[(\psi$ dsiqs- $\psi \mathrm{qs}$ ids $)]$

$=(3 / 2)(\mathrm{p} / 2) \operatorname{Lm}[($ idriqs- iqr ids $)]$

\section{SIMULINK IMPLIMENTATION OF DFIG}

Simulink is a software package for modeling, simulating, and analyzing dynamical systems. It supports linear and nonlinear systems, modeled in continuous time, sampled time, or a hybrid of the two. Systems can also be multirate, i.e., have different parts that are sampled or updated at different rates. For modeling, Simulink provides a graphical user interface (GUI) for building models as block diagrams, using clickand-drag mouse operations. With this interface, you can draw the models just as you would with pencil and paper (or as most textbooks depict them). This is a far cry from previous simulation packages that require you to formulate differential equations and difference equations in a language or program. Simulink includes a comprehensive block library of sinks, sources, linear and nonlinear components, and connectors. You can also customize and create your own blocks. For information on creating your own blocks, see the separate Writing S-Functions guide.

\section{A. Simulink Implementation of Mechanical System}

The electromagnetic torque developed is

$\mathrm{Te}=2 \mathrm{Hd} / \mathrm{dt}(\omega \mathrm{m})+\mathrm{Bm} \omega \mathrm{m}+\mathrm{Tl}$

Where $\mathrm{Te}=\mathrm{Tg}$ and $\mathrm{T}$ shaft $=\mathrm{Tl}$ ) 


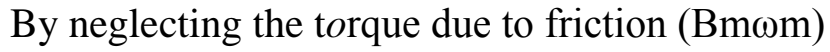

$\mathrm{Te}-\mathrm{Tl}=2 \mathrm{Hd} / \mathrm{dt}(\omega \mathrm{m})$

From above equation, the rotor speed $(\omega \mathrm{m})$ is

$\omega \mathrm{m}=(\mathrm{Te}-\mathrm{Tl}) /(2 \mathrm{Hg}) \mathrm{dt}$

$=(0.5 / \mathrm{Hg})(\mathrm{Te}-\mathrm{Tl}) \mathrm{dt}$

similarly the turbine speed is

$\omega \mathrm{t}=(\mathrm{Tl}-\mathrm{Tw}) /(2 \mathrm{Hw}) \mathrm{dt}$

$=(0.5 / \mathrm{Hw})(\mathrm{Tl}-\mathrm{Tw}) \mathrm{dt}$

from the above equations, we have

$\mathrm{Tl}=\mathrm{Km}(\theta \mathrm{m}-\theta \mathrm{t})=\mathrm{Km}(\omega \mathrm{m}-\omega \mathrm{t}) \mathrm{dt}$

where $\theta=\omega \mathrm{dt}$

In the doubly fed induction generator is running at a specified speed with the stator which is not connected from the grid. The rotor is suddenly excited with the slip frequency voltages derived from voltage regulator so as to produce commanded open circuit stator terminal voltage. The specified operating conditions and final values of the variables reached in the steady state are all saved in the workspace to serve as initial conditions in a subsequent simulation.

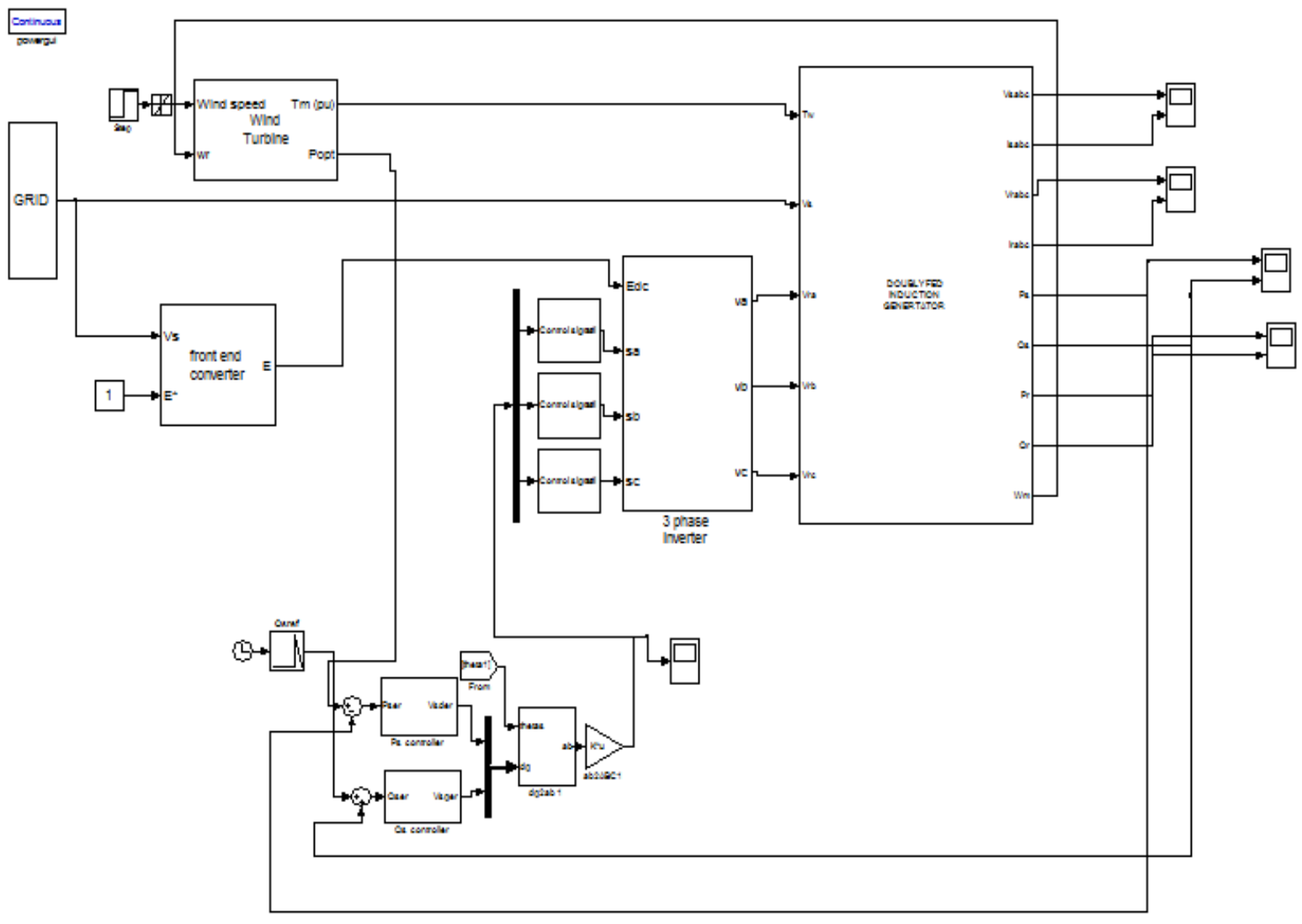

Fig.2: DFIG with PI Controller 


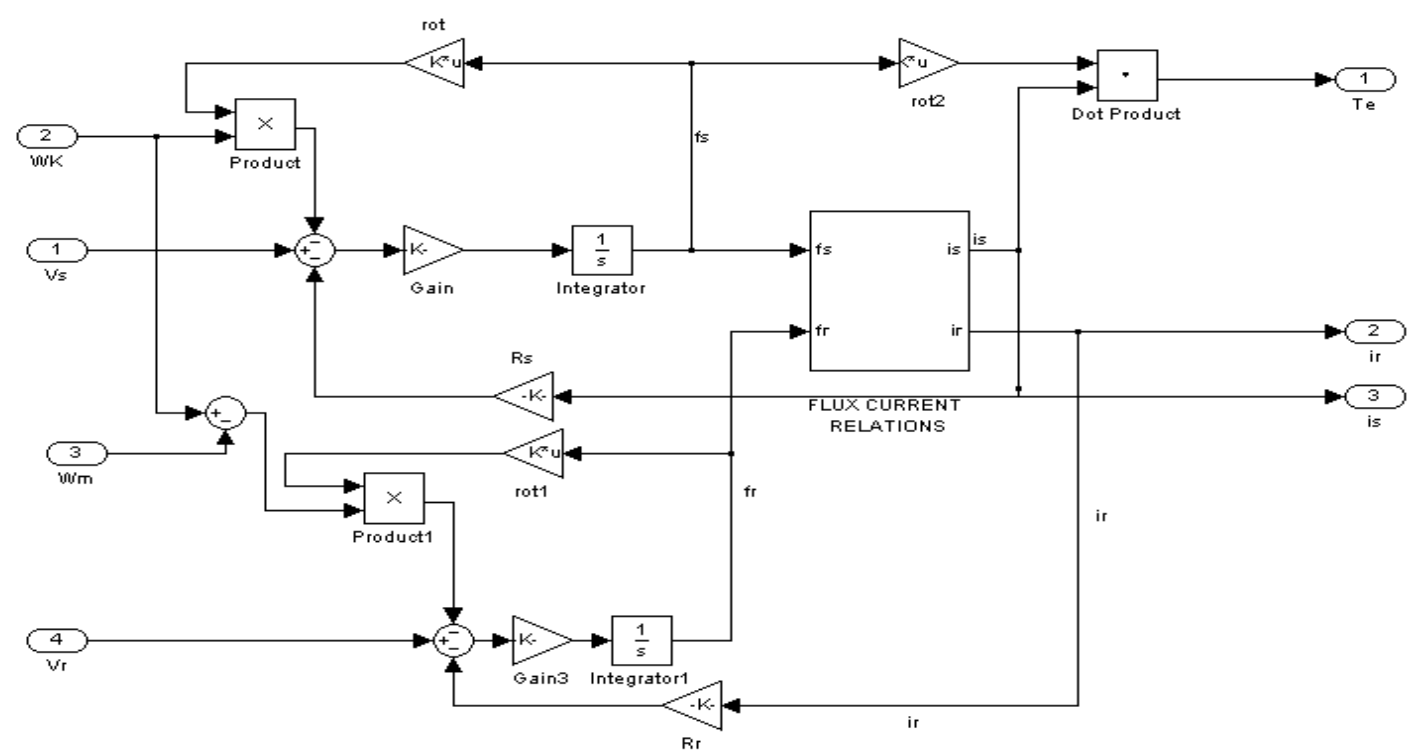

Fig.3: Dynamic Model of Induction Machine in Arbitrary Reference Frame

The rotor-side converter is used to control the wind turbine output power and the voltage measured at the grid terminals. The power is controlled in order to follow a pre-defined power-speed characteristic, named tracking characteristic. This characteristic is illustrated by the ABCD curve superimposed to the mechanical power characteristics of the turbine obtained at different wind speeds.

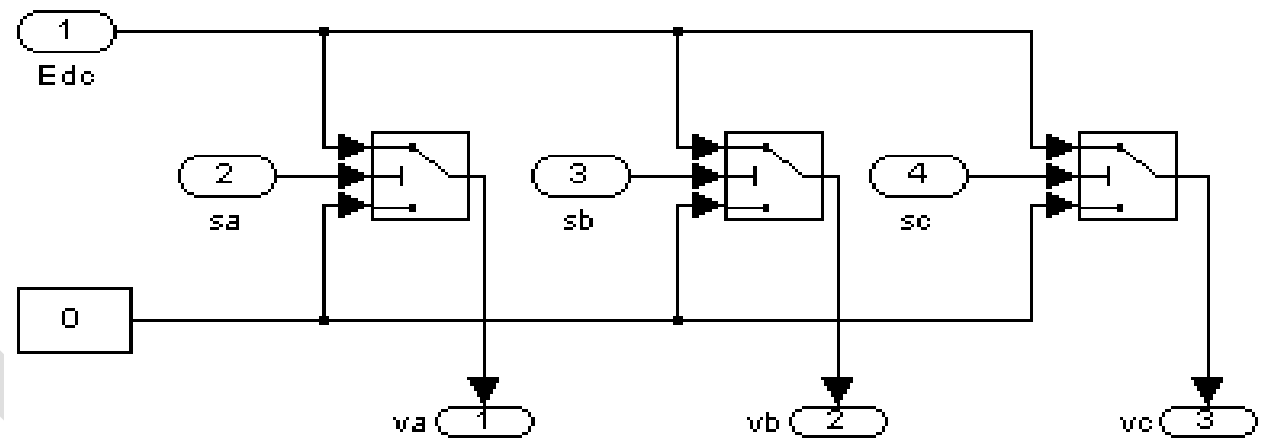

Fig.4: Simulink Diagram for Rotor Side Converter

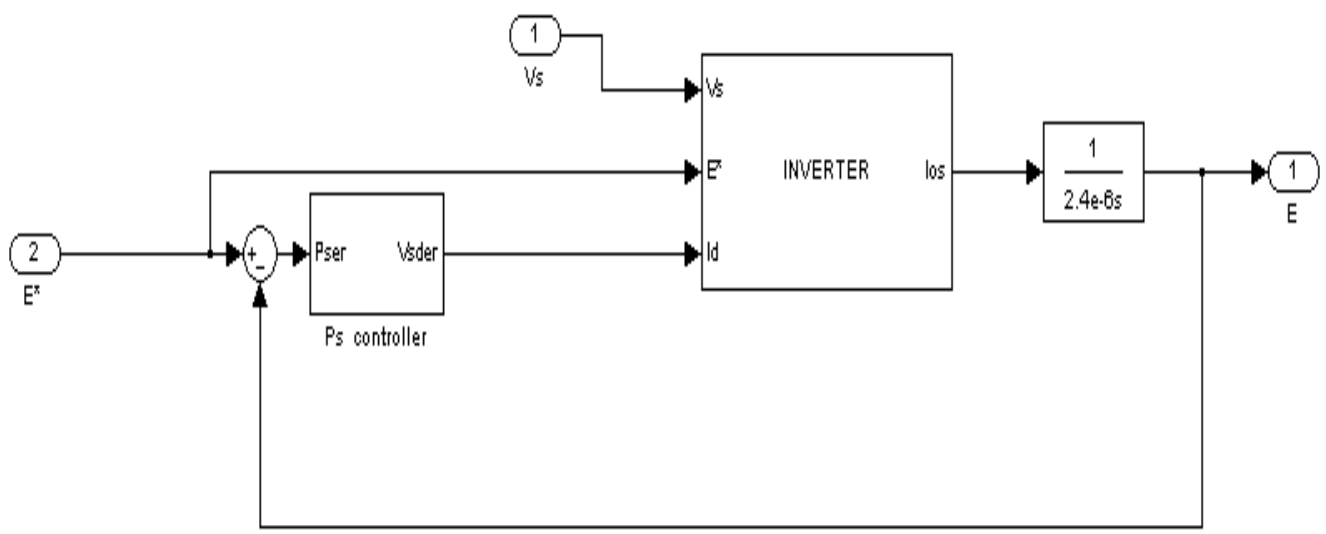

Fig.5: Simulink Diagram for Stator Side Converter 


\section{B. Neural Networks Artificial}

Numerous advances have been made in developing intelligent systems, some inspired by biological neural networks. Researchers from many scientific disciplines are designing artificial neural networks to solve a variety of problems in pattern recognition, prediction, optimization, associative memory, and control. Conventional approaches have been proposed for solving these problems. Although successful applications can be found in certain well-constrained environments, none is flexible enough to perform well outside its domain. ANNs provide exciting alternatives, and many applications could benefit from using them. This article is for those readers with little or no knowledge of ANNs to help them understand the other articles in this issue of Computer.

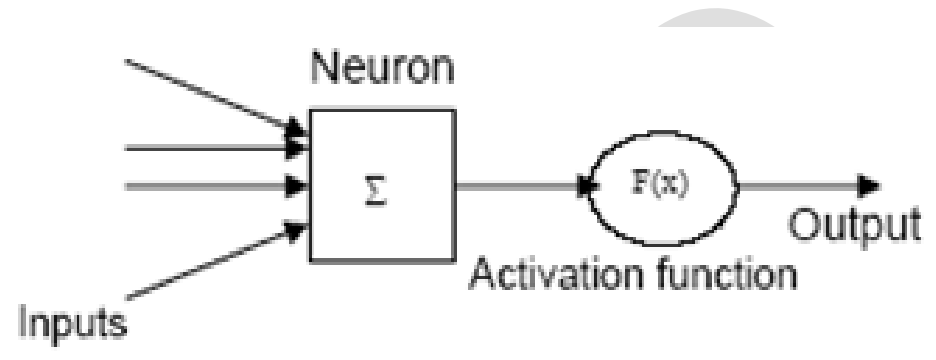

Fig. 6 Simple Artificial Neuron

The long course of evolution has given the human brain many desirable characteristics not present Invon Neumann or modern parallel computers. These include massive parallelism, distributed representation and computation, learning ability, Generalization ability. The above figure shows three phase open circuit voltages $e_{a}, e_{b}, e_{c}$ which are displaced by 120 electrical degrees apart. Hence from this we can say that power is generated from doubly fed induction generator.

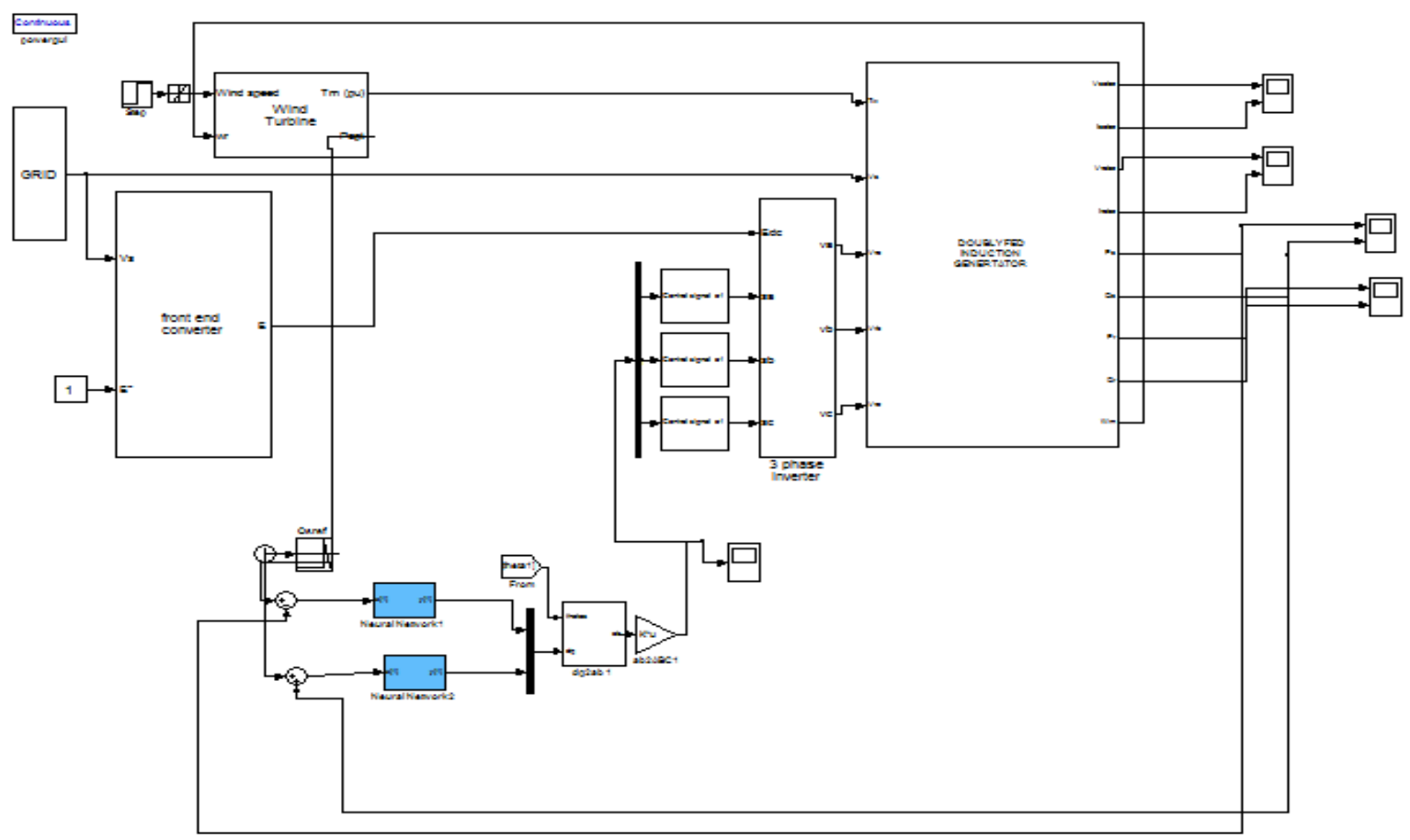

Fig.7 DFIG with ANN 
DOI : https://dx.doi.org/10.26808/rs.st.i7v6.02

International Journal of Advanced Scientific and Technical Research

Issue 7 volume 6 Nov.- Dec. 2017

Available online on http://www.rspublication.com/ijst/index.html

ISSN 2249-9954

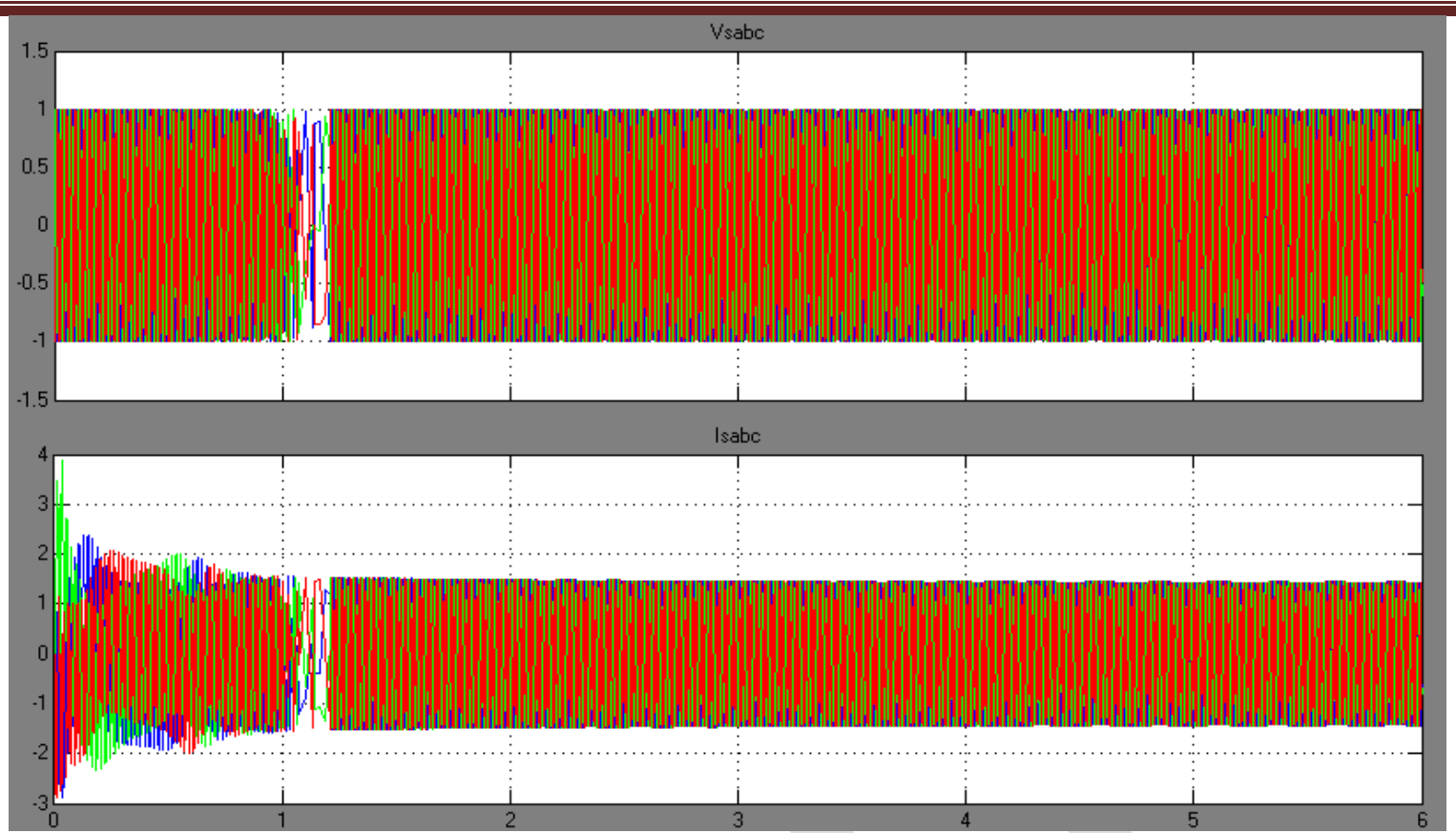

Fig.8: Three Phase Stator Output Voltage and Current using PI controller

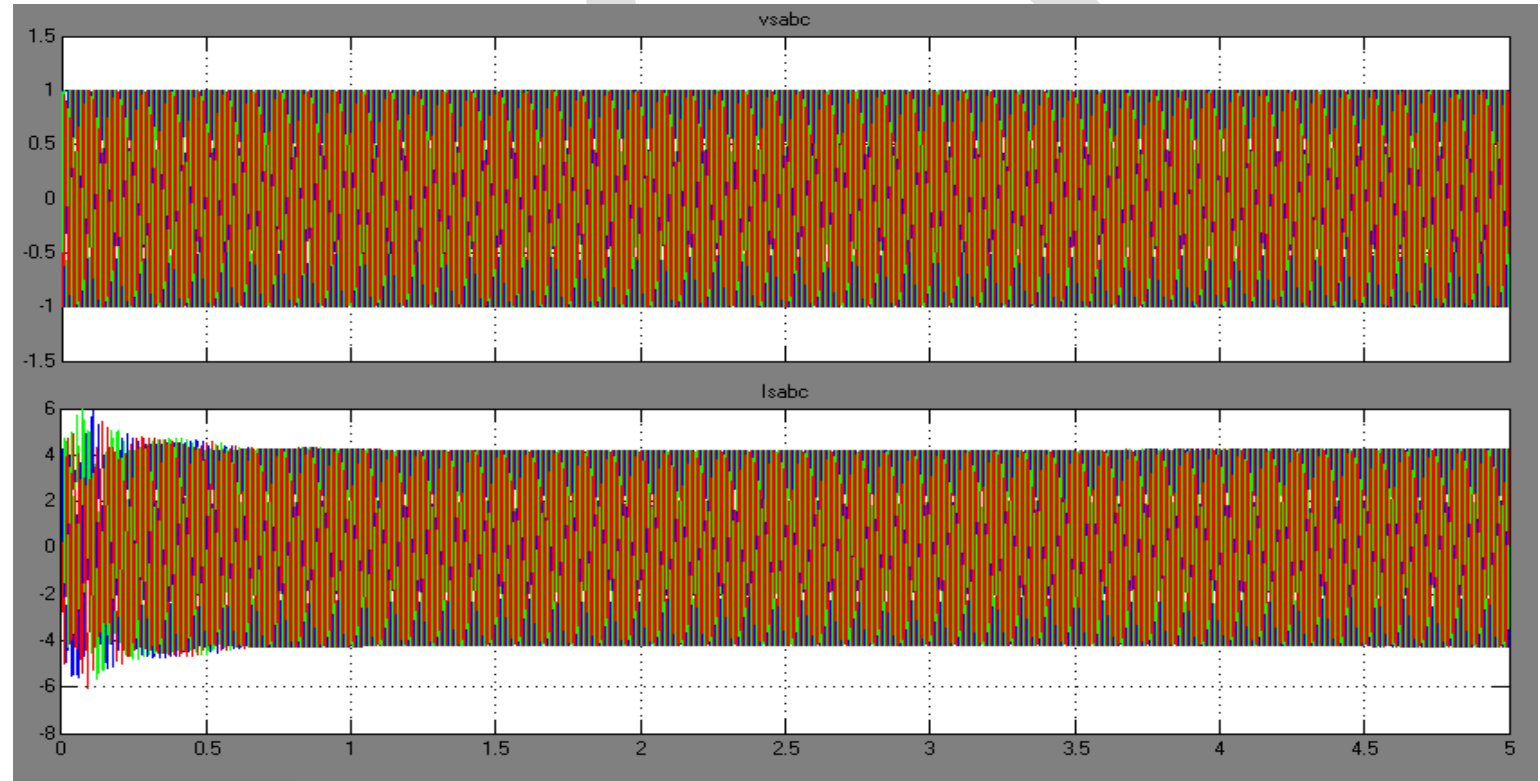

Fig.9: Three Phase Stator Output Voltage and Current using ANN

\section{CONCLUSION}

In this Doubly fed induction generator is modeled in vectorized form in the synchronous frame associated with the stator voltage space vector, and also voltages and currents are controlled by using PI and ANN controllers by injecting the rotor voltage (slip frequency). As compared the response between these two controllers PI \& ANN. The better result was found in the ANN controller. 


\section{REFERENCES}

[1] A.Dendouga, R. Abdessemed, M. L. Bendaas and A. Chaiba LEB-Research Laboratory, Department of Electrical engineering, Batna University, Algeria (2007)"Decoupled Active and Reactive Power Control of a Doubly-Fed Induction Generator (DFIG)", proceedings of the $15^{\text {th }}$ Mediterranean conference on control \& Automation, July 27-29, Athens,-Greece.

[2] B.ChittiBabu, K.B.Mohanty, "Control of Double-Output Induction Machine for Variable Speed Wind Energy Conversion System Using Dynamic Vector Approach".

[3] ChittiBabu B, K.B.Mohanty, C. Poongothai (2009), "Steady State Analysis and Control of Wind Turbine Driven Double-Output Induction Generator",3rd International Conference on Power Electronics Systems and Applications.

[4] S. K Salman and BabakBadrzadeh School of Engineering, The Robert Gordon University, IEEE paper on, "New Approach for modeling of Doubly-Fed Induction Generator (DFIG) for gridconnection studies".

[5] S. Muller, M. Deicke and R.W. De Doncker (2002), "Doubly fed induction generator systems for wind turbine", IEEE Industry Applications Magazine, Vol.8, No. 3, pp. 26-33.

[6] Peterson A. Analysis (2003), "Modeling and control of Doubly-Fed Induction Generators for windturbines". Licentiate thesis; Chalmers University, Gutenberg, Sweden.

[7] Ong CM (1998) "Dynamic Simulation of electric machinery using MATLAB/SIMULINK", Prentice Hall.

[8] BranislavDosijanoski, M.Sc. Student, Faculty of Electrical Engineering and Information Technologies, University (2009), "Simulation of Doubly-Fed Induction Generator in a Wind Turbine", XI International PhD Workshop OWD 2009, 17-20 October. 